\title{
ASPECTOS HISTOLÓGICOS DA GLÂNDULA MAMÁRIA DE QUATI (Nasua
} nasua, LINNAEUS 1766)

\author{
Thelma Michella Saddi ${ }^{*}$, Flávio de Rezende Guimarães ${ }^{1}$, Mônica Sousa Campos ${ }^{2}$, \\ Marcos Vinicios Borges Galdino ${ }^{3}$, Fernanda Cristina Alcantara dos Santos ${ }^{4}$. \\ 1 Doutores, Professores na Faculdade de Agronomia, Medicina Veterinária e \\ Zootecnia, UFMT, Cuiabá, Brasil. \\ 2 Doutoranda do Instituto de Biociências, Letras e Ciências Exatas, UNESP, São \\ José do Rio Preto, Brasil. \\ 3 Graduado. Faculdade de Biomedicina, UFG, Goiânia, Brasil. \\ 4 Doutora, Professora no Instituto de Ciências Biológicas, UFG, Goiânia, Brasil. \\ *thelma.saddi@gmail.com
}

Recebido em: 08/04/2016 - Aprovado em: 30/05/2016 - Publicado em: 20/06/2016 DOI: 10.18677/Enciclopedia_Biosfera_2016_121

Os quatis (Nasua nasua, Linnaeus 1766) são procionídeos amplamente distribuídos nas florestas sul-americanas. Possuem elevada prolificidade e formam grupos matriarcais de até mais de 30 indivíduos, nos quais os filhotes são amamentados até os cinco meses. A glândula mamária, apesar de apresentar semelhanças entre os mamíferos, sofre variações entre as espécies quanto à aparência, número e disposição e, sua estrutura histológica altera-se de acordo com o sexo, a idade e o estado fisiológico. Considerando que os estudos morfológicos de quatis são escassos bem como a importância da glândula mamária na manutenção da vida, o presente estudo buscou caracterizar morfologicamente a glândula mamária de fêmeas de quatis adultos. Para tal, foram utilizadas duas fêmeas adultas de $N$. nasua, cedidas pelo CETAS/IBAMA-GO. O estudo foi aprovado pelo Comitê de Ética em Pesquisa da Universidade Federal de Goiás e a eutanásia foi realizada segundo normativa do Conselho Federal de Medicina Veterinária. Os animais tiveram seus tecidos fixados e seus órgãos foram coletados, lavados, desidratados, clarificados e incluídos sendo, posteriormente, seccionados a $5 \mu \mathrm{m}$ em micrótomo rotativo manual. Foram utilizadas as técnicas histoquímicas de hematoxilina-eosina, reticulina de Gömöri, resorcina, picrossirius e ácido periódico de Schiff (P.A.S.) bem como algumas técnicas de imunohistoquímica (PCNA e p63). Os achados revelaram que as glândulas mamárias de fêmeas de $N$. nasua assemelham-se quanto às características morfológicas aos animais domésticos e aos mãos-peladas, entretanto diferem em número, no que diz respeito aos carnívoros domésticos. A atividade proliferatica do epitélio glandular mostrou-se discreta, porém presente, mesmo as fêmeas estando em anestro.

PALAVRAS-CHAVE: histologia, Procyonidae, reprodução. 


\title{
HISTOLOGICAL ASPECTS OF MAMMARY GLANDS OF QUATI (Nasua nasua, LINNAEUS 1766)
}

\begin{abstract}
Coatis (Nasua nasua, Linnaeus 1766) are procyonids widely distributed in South American forests. They have high prolificity and form matriarchal groups of more than 30 individuals. The cubs are breastfed up to five months. The mammary gland, despite having similarities among mammals, suffers variations between species in terms of appearance, number and arrangement. Its histological structure changes depending on the sex, age and physiological state. Morphological studies of coatis are scarce as well as the importance of the mammary gland in the maintenance of life. Thus, this study aimed to morphologically characterize the mammary gland of adult female coatis. To this end, we used two adult $\mathrm{N}$. nasua females, provided by the CETAS/ IBAMA-GO. The study was approved by the Ethics Committee of the Federal University of Goiás and euthanasia was performed according to regulations of the Federal Council of Veterinary Medicine. The organs were collected, washed, fixed, dried, clarified and included in paraffin. Subsequently, they were sectioned at $5 \mu \mathrm{m}$ of thickness in manual rotary microtome. Histochemical techniques applied to evaluate the glands were hematoxylin-eosin, Gomori reticulin, resorcinol, Picrossirius, periodic acid-Schiff (P.A.S.) and some immunohistochemical techniques (PCNA and p63). The findings revealed that mammary glands of female N. narica resemble morphological characteristics of domestic animals and raccoons. It differs, however, in number when compared to the mammary glands of domestic carnivores. The proliferative activity of glandular epithelium is present but discreet, even the females being in anestrus.
\end{abstract}

KEYWORDS: histology, Procyonidae, reproduction.

\section{INTRODUÇÃO}

Os quatis (Nasua nasua) são classificados como pertencentes ao filo Chordata, classe Mammalia, ordem Carnivora e família Procyonidae (WILSON \& REEDER, 2005). São habitantes típicos de áreas florestais (GOMPPER, 1997; ALVES-COSTA et al., 2004, BEISIEGEL \& MANTOVANI, 2006) e considerados os procionídeos mais amplamente distribuídos na América do Sul. São encontrados desde o norte da Colômbia e Venezuela até o norte da Argentina (GOMPPER \& DECKER, 1998; BEISIEGEL, 2001; CUARÓN et al., 2004). No Brasil, ocorrem em todos os biomas, contudo, com menor frequência, na região nordeste (BARROS \& FRENEDOZO, 2010; BEISIEGEL \& CAMPOS, 2013).

Os quatis são animais de hábitos diurnos e que vivem em grupos sociais matriarcais compostos por até mais de 30 indivíduos, entre fêmeas, filhotes e machos jovens (BARROS \& FRENEDOZO, 2010). São animais com elevada prolificidade, podendo uma fêmea parir até sete filhotes após 77 dias de gestação (EISENBERG, 1989). As fêmeas são encontradas solitárias apenas no período em que constroem ninhos nas árvores e amamentam os filhotes durante as primeiras semanas de vida (GOMPPER \& DECKER, 1998; BEISIEGEL \& MANTOVANI, 2006; BARROS \& FRENEDOZO, 2010). Os filhotes são amamentados até os cinco meses (BEISIEGEL, 2001).

A glândula mamária é uma característica exclusiva dos mamíferos, cuja função nas fêmeas é secretar leite (FEITOSA, 2008; ROSS \& PAWLINA, 2008). 
Embora a estrutura básica seja similar nos mamíferos, há amplas variações entre as espécies quanto à quantidade relativa dos componentes secretados, aparência, número e disposição das mamas (ELLENPORT, 1986). A situação comumente observada nos carnívoros domésticos é a de, nos cães, de forma geral, existirem cinco pares de mamas (dez glândulas mamárias) (DYCE et al., 2004; COLVILLE \& BASSERT, 2010) e nos gatos, quatro pares (oito glândulas mamárias) denominadas em ambos, de acordo com a localização, como torácicas, abdominais e inguinais (ELLENPORT, 1986; BANKS, 1992; ROSS \& PAWLINA, 2008; COLVILLE \& BASSERT, 2010).

O órgão é uma glândula túbulo-alveolar (CALHOUN \& STINSON, 1982; GAONA et al., 1999; SAMUELSON, 2007) composta, sendo considerada uma glândula sudorípara modificada (GAONA et al., 1999) e muito aumentada (COLVILLE \& BASSERT, 2010).

A estrutura histológica das glândulas mamárias sofre alteração de acordo com o sexo, a idade e o estado fisiológico (CALHOUN \& STINSON, 1982; GAONA et al., 1999; TOILLON et al., 2007), sendo sensíveis à ação dos hormônios esteróides que atuam por via autócrina, parácrina e endócrina (BANKS, 1992; TOILLON et al., 2007).

Os estudos envolvendo a morfologia dos quatis são escassos e a abordagem comumente dada aos estudos envolvendo a glândula mamária são, na maioria, voltados às alterações oncológicas nos animais domésticos. Dessa forma, considerando a importância da glândula mamária, o presente estudo buscou caracterizar morfologicamente tal estrutura, em fêmeas de quatis ( $N$. nasua).

\section{MATERIAL E MÉTODOS}

\section{Animais}

Foram utilizadas duas fêmeas adultas de quatis (Nasua nasua), cedidas pelo Instituto Brasileiro do Meio Ambiente e dos Recursos Naturais Renováveis IBAMA, via Centro de Triagem de Animais Silvestres (CETAS) do município de Goiânia, Goiás, Brasil, para destinação científica ( $n$ ำ licença 98/2011). Os estudos envolvendo tais animais foram aprovados pelo Comitê de Ética em Pesquisa da Universidade Federal de Goiás (CEP/ UFG, protocolo 235/2011), sendo a eutanásia realizada de acordo com a Resolução n 14, de 20 de junho de 2002, do Conselho Federal de Medicina Veterinária. Assim, a eutanásia foi realizada por meio de associação de tiletamina/zolazepam $(10 \mathrm{mg} / \mathrm{Kg})$, por via intramuscular (IM), para contenção química e indução anestésica, seguida de administração de tiopental $(12,5 \mathrm{mg} / \mathrm{KG})$, via intravenosa (IV), para atingir o plano anestésico, após o qual foi mantida a administração deste anestésico geral injetável a 2,5\% (IV) até o óbito por sobrecarga anestésica.

\section{Microscopia de Luz}

Os animais foram fixados com solução de formaldeído 4\% (em tampão fosfato $0,1 \mathrm{M}, \mathrm{pH} 7,2$ ) por meio de perfusão via artéria carótida comum, injeção nas grandes cavidades e infiltração das grandes massas musculares. Depois da fixação, os tecidos foram colhidos e lavados em água, desidratados em etanol, clarificados em xilol, embebidos em parafina (Histosec, Merck, Darmstadt, Germany) e seccionados a $5 \mu \mathrm{m}$ em micrótomo rotatório manual (Leica RM2155, Nussloch, 
Germany). Os cortes foram corados com hematoxilina-eosina, picrossíriushematoxilina, reticulina de Gömöri, resorcina-fucsina de Weigert e reação do ácido periódico de Schiff. Os tecidos foram analisados ao microscópio de luz (Olympus BX 60, Olympus, Japan) e as imagens foram digitalizadas no programa DP-BSW v.3.1 (Olympus, Japan) e em um sistema de slide virtual BX 61 VS (Olympus, Tokyo, Japan).

\section{Imunohistoquímica}

Os cortes histológicos foram submetidos a reações de imunohistoquímica para detecção de PCNA e p63. Anticorpos primários para PCNA (mouse monoclonal $\operatorname{lgG}_{2 a}$, SC 56, Santa Cruz Biotechnology, CA, USA) e p63 (mouse monoclonal $\operatorname{lgG}_{2 a}, 4 A 4$, sc-8431, Santa Cruz Biotechnology) foram aplicados em uma diluição de 1:100. Polímeros (Post Primary Block and Polymer, Novocastra TM, RE7260-k, Newcastle Upon Tyne, UK; DAKO Envision ${ }^{\mathrm{tm}}+$ Dual link system-HRP, K4061; DAKO, North America, Inc., Carpinteria, California, USA) foram utilizados como anticorpo secundário, de acordo com os procedimentos descritos pelo fabricante. Os cortes foram corados com diaminobenzidina e contracorados com hematoxilina de Harris. Os cortes histológicos foram analisados ao microscópio de luz (Olympus BX60, Olympus, Japan).

\section{RESULTADOS}

As fêmeas de quati em estudo apresentaram três pares de glândulas mamárias, sendo um par abdominal cranial, um abdominal caudal e o terceiro par, de mamas inguinais. Os três pares de mamas se encontravam, morfologicamente, inativos. Nas fêmeas de quatis havia a presença de pelos em abundância na região das glândulas mamárias e estes, apesar de recobrirem grande parte das papilas, não emergiam delas. As papilas mamárias das fêmeas de quatis estudadas eram despigmentadas e apresentaram formato arredondado.

Histologicamente, as glândulas mamárias das fêmeas estudadas eras formadas por lóbulos de glândulas tubuloalveolares que se distribuiam ao longo de uma espessa camada de tecido conjuntivo denso e adiposo, contígua à derme. Cada lóbulo mamário continha uma glândula tubuloalveolar individualizada que se abria em um ducto excretor. Os ductos excretores convergiam para a região da papila mamária, onde se abriam individualmente na superfície da pele (Figura 1a).

Cada lóbulo mamário apresentou uma grande quantidade de ductos intralobulares de diâmetros variáveis (Figura 1b), com a maioria dos ductos apresentando lúmen reduzido ou ausência de luz. Os ductos intralobulares eram revestidos por um epitélio pseudoestratificado, com células luminais e basais (Figura 1c),

Os ductos intralobulares são envoltos por um tecido conjuntivo intralobular rico em fibras colágenas e elásticas (Figuras $2 a$ e $2 c$ ). Fibras reticulares foram observadas exclusivamente na base do epitélio ductal (Figura $2 b$ ). A reação com o P.A.S. demonstrou quantidades discretas de secreção glicoproteica armazenada no lumen ductal (Figura 2d). 

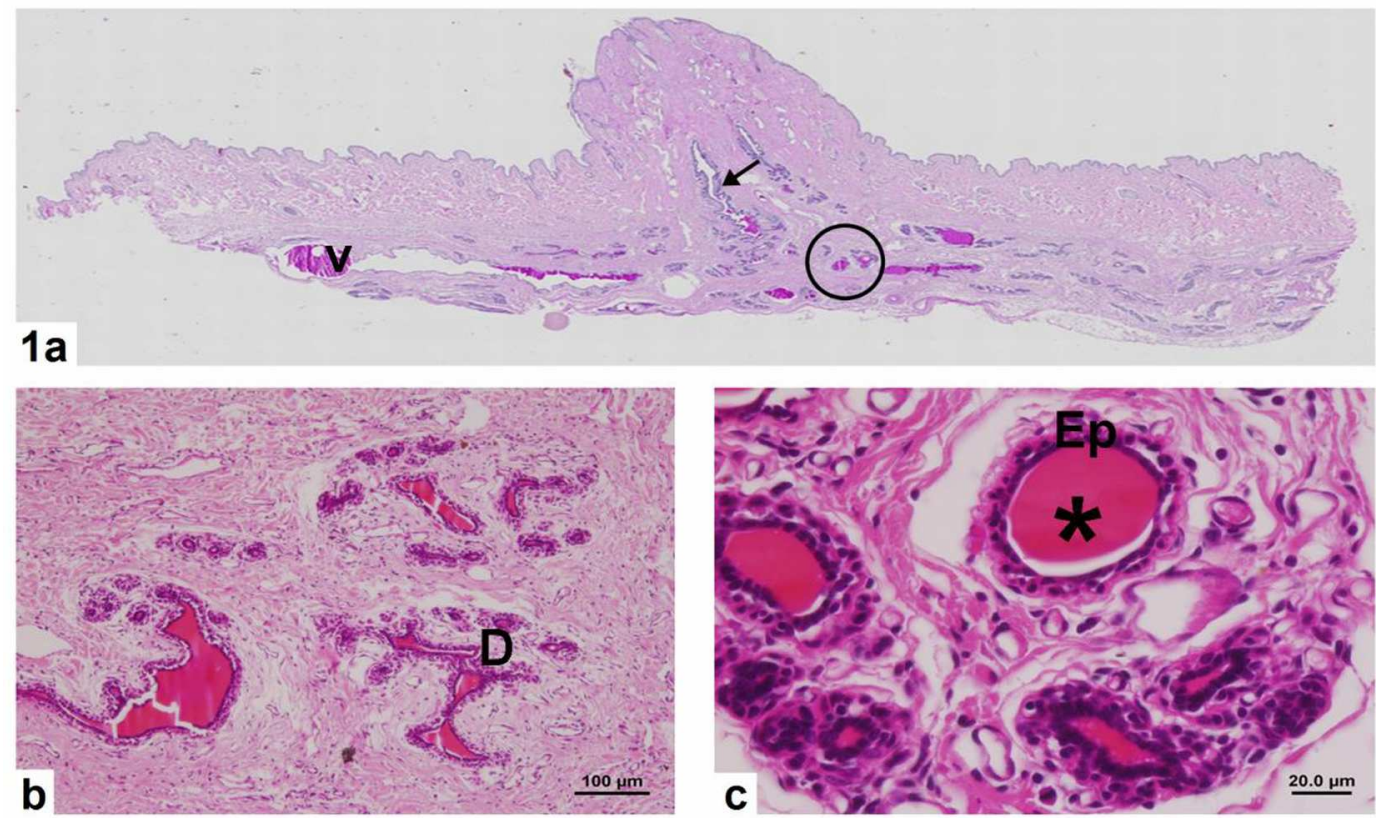

FIGURA 1 Fotomicrografia de glândula mamária de quati. (a) Visão panorâmica de um corte total de mama de quati corado pelo ácido periódico de Schiff (P.A.S.). No lobo mamário, cada grupo de ductos intralobulares (área circulada) é circundado por tecido conjuntivo intralobular e desemboca em um ducto excretor (seta) no centro da papila mamária. Vaso sanguíneo (V). (b) Detalhe do lobo mamário evidenciando os ductos intralobulares (D). Coloração: hematoxilina-eosina. (c) Os ductos são revestidos por epitélio pseudoestratificado (Ep) e, em sua maioria, não apresentam lumen ou tem luz reduzida $\left({ }^{*}\right)$.Coloração: hematoxilinaeosina.
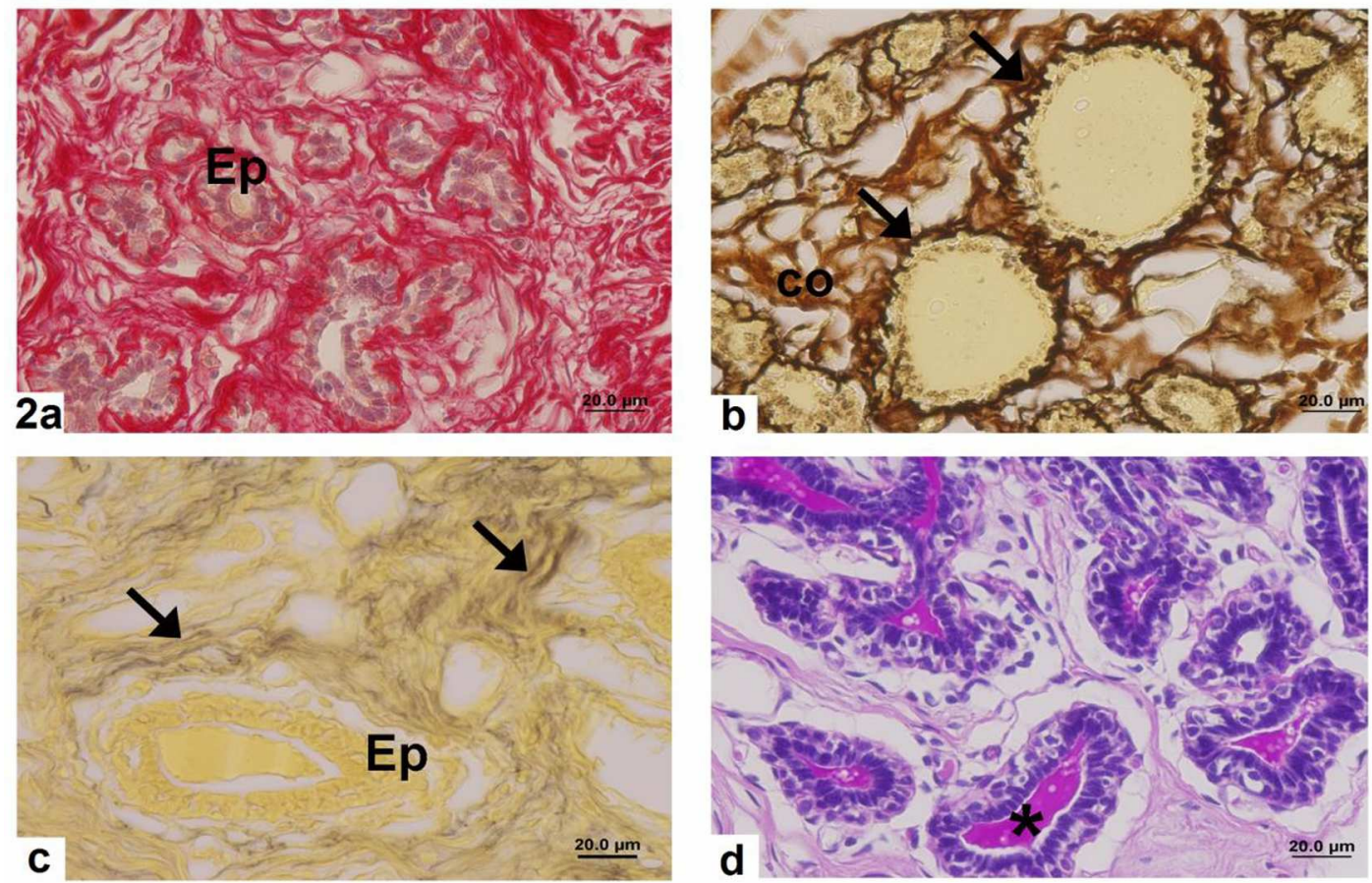

FIGURA 2 Fotomicrografia de glândula mamária de quati. (a) Abundância em colágeno (vermelho) no tecido conjuntivo intralobular. Coloração: picrossirius-hematoxilina. (b) Fibras reticulares (setas) na base do epitélio de revestimento dos ductos mamários (D). Colágeno (CO). Coloração: 
reticulina de Gömöri. (c) Fibras elásticas (setas) formam uma rede de fibrilas esparsas no tecido conjuntivo interlobular. Coloração: resorcinafucsina de Weigert. (d) Secreção glicoproteica no lumen dos ductos mamários $\left(^{*}\right)$. Coloração: P.A.S.

A reação imunohistoquímica para PCNA demonstrou que embora a glândula mamária esteja em um estado de inatividade, as células ductais apresentaram uma atividade mínima de proliferação celular (Figura 3a). A presença de células basais no epitélio de revestimento foi confirmada pela marcação imunohistoquímica para a proteína p63 (Figura 3b).
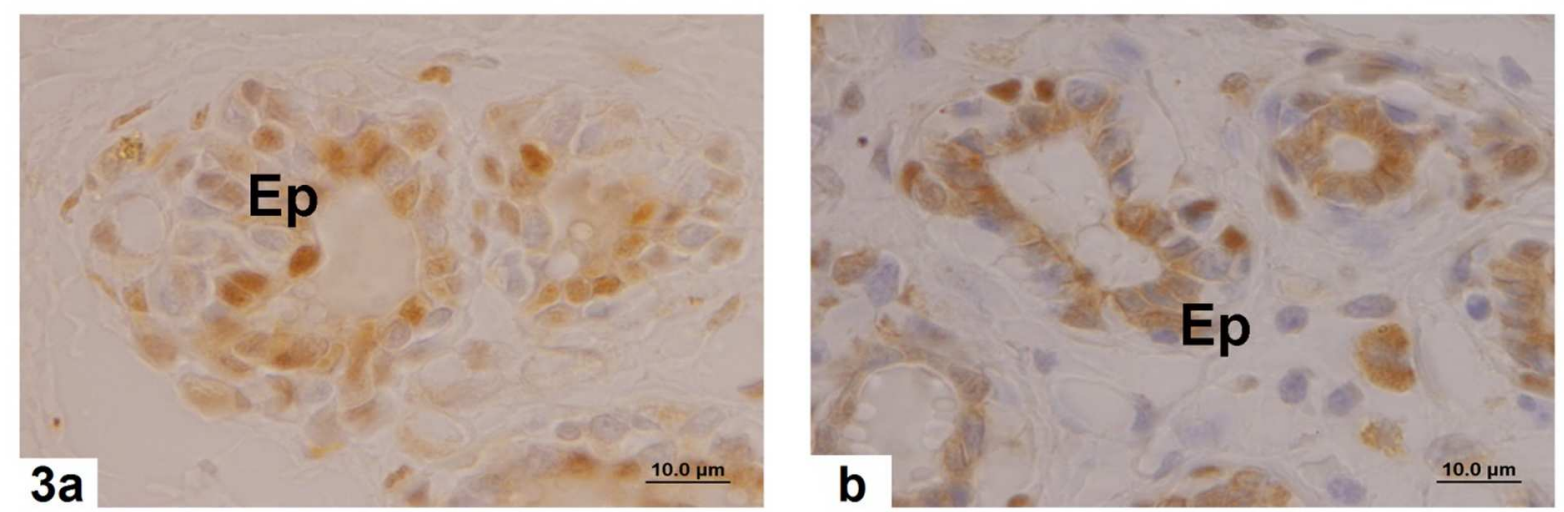

FIGURA 3 Fotomicrografia de glândula mamária de quati. (a) Células PCNA-positivas no epitélio ductal da mama de quatis. (b) Células p63-positivas no epitélio dos ductos mamários

\section{DISCUSSÃO}

As fêmeas de quati do presente estudo possuíam três pares de glândulas mamárias que, designadas de acordo com a localização anatômica, foram classificadas como um par de glândulas mamárias abdominais craniais, um par abdominal caudal e um par inguinal. A ausência das mamas torácicas também ocorre em Procyon cancrivorus, outro membro da família Procyonidae conhecido popularmente como mão-pelada, nos quais a mesma disposição dos pares de glândulas mamárias foi observada (BELLATINE et al., 2010). No entanto, essa disposição ocorre de forma diferente do que é comumente observado nos carnívoros domésticos, onde nos cães, de forma geral, existem cinco pares de mamas (dez glândulas mamárias) (ELLENPORT, 1981; DYCE et al., 2004) e nos gatos, quatro pares (oito glândulas mamárias) distribuídas em ambos, como torácicas, abdominais e inguinais (DYCE et al., 2004). Esta diferença possivelmente está relacionada ao número de progênie gerada por cada espécie. Quatis podem parir até sete filhotes (EISENBERG, 1989), portanto o número de glândulas e de papilas mamárias seria, em geral, suficiente para alimentar os filhotes no pós-parto.

As glândulas mamárias em diferentes espécies são recobertas por pelos que escondem completamente as papilas mamárias (DYCE et al., 2004). Nas fêmeas de quatis há a presença de pelos em abundância na região das glândulas mamárias e estes, apesar de recobrirem em parte as papilas, não emergem destas, somente da periferia. BELLATINE et al, (2010) também verificaram a presença em abundância de pelos nas glândulas mamárias de fêmeas de mãos-peladas, inclusive emergindo das papilas mamárias. 
As papilas mamárias das fêmeas de quatis estudadas apresentaram formato arredondado, assemelhando-se ao formato encontrado em mãos-peladas e também em cadelas. Com relação à pigmentação, as papilas mamárias das duas fêmeas de quatis do presente estudo apresentaram papilas mamárias despigmentadas. Estudo em mãos-peladas revelaram papilas mamárias despigmentadas em dois animais e pigmentada em um deles (BELLATINE et al., 2010).

Histologicamente, a glândula mamária de fêmeas de quatis mostrou-se semelhante a dos outros mamíferos domésticos, pois apresentou características de uma glândula túbulo-alveolar (BANKS, 1992; GAONA et al., 1999). Também se assemelhou aos mãos-peladas e aos mamíferos domésticos ao ter se apresentado formada por um sistema de lóbulos e ductos ramificados, distribuídos em um estroma de tecido conjuntivo e adiposo com alta vascularização (BELLATINE et al., 2010).

A presença de lóbulos mamários com uma grande quantidade de ductos intralobulares de diversos diâmetros associados ao fato de os ductos excretores convergirem para a região da papila mamária e abrirem-se individualmente na superfície da pele assemelha-se ao que ocorre nos mamíferos domésticos (BANKS, 1992; DYCE et al., 2004) e também em mãos-peladas (BELLATINE et al., 2010).

As glândulas mamárias das fêmeas de quatis estavam em estado inativo, apresentando a maioria dos ductos com lúmen reduzido ou ausência de luz. Essa situação é característica de fêmeas, como cadelas, pois fora do período de lactação (fase de inatividade secretora) há um colapso gradual dos alvéolos que deixam de secretar (e se esvaziam) ao mesmo tempo em que há uma proliferação intensa do tecido conjuntivo (GAONA et al., 1999). Além disso, verificou-se, nos quatis, através do teste de imunohistoquímica para PCNA que embora a glândula mamária estivesse em estado de inatividade, as células ductais apresentavam uma discreta atividade de proliferação celular.

Os ductos intralobulares das glândulas mamárias dos animais do presente estudo mostraram-se revestidos por epitélio pseudoestratificado prismático, da mesma forma que em mãos-peladas e em mamíferos domésticos (BANKS, 1999; BELLATINE et al., 2010). A presença de células basais também já foi identificada em mãos-peladas, bem como a observação de fibras colágenas em grande quantidade, imersas no tecido conjuntivo intralobular (BELLATINE et al., 2010). A localização das fibras reticulares, observadas exclusivamente na base do epitélio ductal, certamente está relacionada à sustentação da estrutura.

Com relação ao resultado da reação com o P.A.S. foi verificada situação semelhante, em fêmeas de mãos-peladas fora do período de lactação, quando BELLATINE et al., (2010), demonstraram quantidades reduzidas de secreção glicoproteica armazenada no lúmen ductal. Assim, as glândulas mamárias de fêmeas de $N$. nasua assemelham-se quanto as características morfológicas aos animais domésticos e aos mãos-peladas, entretanto diferem em número, no que diz respeito aos carnívoros domésticos.

Considerando que estudos morfológicos em animais silvestres são escassos, acredita-se que este estudo auxilie futuros estudos e ou mesmo intervenções clínico-patológicas e cirúrgicas tanto na referida espécie bem como em outros procionídeos. 


\section{AGRADECIMENTOS}

Ao Instituto Brasileiro do Meio Ambiente e dos Recursos Naturais Renováveis - IBAMA e ao Centro de Triagem de Animais Silvestres (CETAS) do município de Goiânia, Goiás, Brasil pela liberação dos animais, sem os quais esta pesquisa teria sido inviabilizada.

\section{REFERÊNCIAS}

ALVES-COSTA, C. P.; FONSECA, G. A. B.; CHRISTOFARO, C. Variation in the diet of the brown-nosed coati (Nasua nasua) in southeastern Brazil. Journal of Mammalogy, v. 85, n. 3, p. 478-482, 2004. Disponível em: <http://jmammal.oxfordjournals.org/content//mammal/85/3/478.full.pdf> doi: http:// dx.doi.org/10.1644/1383945 Acesso em: 26 nov. 2015.

BANKS, W. J. Histologia veterinária aplicada. 2. ed. São Paulo: Manole Ltda, 1992. $629 \mathrm{p}$.

BARROS, D.; FRENEDOZO, R. C. Uso do habitat, estrutura social e aspectos básicos da etologia de um grupo de quatis (Nasua nasua Linnaeus, 1766) (Carnivora: Procyonidae) em uma área de Mata Atlântica, São Paulo, Brasil. Biotemas, v. 23, n. 3, p. 175-180, 2010. Disponível em: $<$ https://periodicos.ufsc.br/index.php/biotemas/article/view/2175-7925.2010v23n3p 175> doi: http://dx.doi.org/10.5007/2175-7925.2010v23n3p175 Acesso em: 20 set. 2015.

BEISIEGEL, B. M. Notes on the coati, Nasua nasua (Carnivora: Procyonidae) in an Atlantic Forest area. Brazilian Journal of Biology, v. 61, n. 4, p. 689-692, 2001. Disponível em: <http://www.scielo.br/scielo.php?script=sci arttext\&pid=S15196984200100040002 0> doi: http://dx.doi.org/10.1590/S1519-69842001000400020 Acesso em: 20 set. 2015.

BEISIEGEL, B.; MANTOVANI, W. Habitat use, home range and foraging preferences of the coati Nasua nasua in a pluvial tropical Atlantic forest area. Journal of Zoology, v. 269, n. 1, p. 77-87, 2006. Disponível em: $<$ https://www.researchgate.net/publication/229711264 Habitat use home range an $\mathrm{d}$ foraging preferences of Nasua nasua in a pluvial tropical Atlantic forest are a $>$ doi: http://dx.doi.org/10.1111/j.1469-7998.2006.00083.x Acesso em: 20 set. 2015.

BEISIEGEL, B. M.; CAMPOS, C. B. Avaliação do risco de extinção do quati Nasua nasua (Linnaeus, 1766) no Brasil. Biodiversidade Brasileira, v. 3, n. 1, p. 269-276, 2013. Disponível em: <http://www.icmbio.gov.br/revistaeletronica /index.php/BioBR/article/view/396> Acesso em: 19 set. 2015.

BELLATINE, T.; MANÇANARES, C. A. F.; FRANCIOLLI, A. L. R.; AMBRÓSIO, C. E.; MARTINS, D. S.; MIGLINO, M. A.; CARVALHO, A. F. Estudo morfofuncional das glândulas mamárias de Mão Pelada, Procyon cancrivorus. Pesquisa Veterinária Brasileira, v. 30, n. 8, p. 689-695, 2010. Disponível em: $<$ http://www.scielo.br/scielo.php?script=sci arttext\&pid=S0100-736X20100008000 14> doi:10.1590/S0100-736X2010000800014 Acesso em: 19 set. 2015. 
CALHOUN, M. L.; STINSON, A. L. W. Tegumento. In: DELLMANN, H. D.; BROWN, E. M. Histologia veterinária. Rio de Janeiro: Guanabara Koogan, 1982. p. 360- 388.

COLVILLE, T.; BASSERT, J. M. Anatomia e fisiologia clínica para medicina veterinária. 2. ed. Rio de Janeiro: Elsevier Ltda, 2010. 543 p.

CUARÓN, A. D.; MORALES, M. A. M.; MCFADDEN, K. W.; VALENZUELA, D.; GOMPPER, M. The status of dwarf carnivores on Cozumel Island, Mexico. Biodiversity and Conservation, v. 13, p. 317-331, 2004. Disponível em: <http://web.missouri.edu/ gompperm/Cuaron\%20et\%20al\%202004\%20Cozumel\%2 0carnivores.pdf> Acesso em: 19 set. 2015.

DYCE, K. M.; SACK, W. O.; WENSING, C. J. G. Tratado de anatomia veterinária. 3. ed. Rio de Janeiro: Elsevier Brasil, 2004. 872 p.

EISENBERG J. F. Order Carnivora (Fissipedia). In: EISENBERG J. F. editor. Mammals of the Neotropics. Chicago: University of Chicago Press, 1989. p.262267.

ELLENPORT, C. R. Aparelho urogenital do carnívoro. In: GETTY, R. Sisson e Grossman's Anatomia dos Animais Domésticos. 5. ed. Rio de Janeiro: Interamericana, 1986. p.1481-1493.

FEITOSA, F. L. F. Semiologia Veterinária: a Arte do Diagnóstico. 2. ed. São Paulo: Roca, 2008. 752p.

GAONA, H. V.; LAVILLE, R. E.; ARCE, S. R. A.; MARTíNEZ, M. P. Distribución de mastocitos del estroma de la glándula mamaria de perra (Canis familiaris), en periodos activo e inactivo. Veterinaria México, v. 30, n. 4, p. 317-321, 1999. Disponível em: <http://www.medigraphic.com/pdfs/vetmex/vm-1999/vm994h.pdf> Acesso em: 19 dez. 2015.

GOMPPER, M. E.; DECKER, D. M. Nasua nasua. Mammalian Species, Lawrence, v. 580, p.1-36, 1998. Disponível em: <http://www.science.smith.edu/msi/pdf/i00763519-580-01-0001.pdf> Acesso em: 19 dez. 2015.

GOMPPER, M. E. Population ecology of the white-nosed coati (Nasua narica) on Barro colorado Island, Panamá. Journal of Zoology, v. 241, p. 441-455, 1997.Disponível em: <http://onlinelibrary.wiley.com/doi/10.1111/i.14697998.1997.tb04836.x/abstract> doi: 10.1111/j.1469-7998.1997.tb04836.x Acesso em: 19 dez. 2015.

ROSS, M. H.; PAWLINA, W. Histologia, texto e atlas em correlação com biologia celular e molécular. 5. ed. Rio de Janeiro: Guanabara Koogan, 2008. 908p.

SAMUELSON, D. A. Tratado de histologia veterinária. Rio de Janeiro: Elsevier, 2007. $527 \mathrm{p}$. 
TOILLON, R.A.; LAGADEC, C.; PAGE, A.; CHOPIN, V.; SAUTIÈRE, P. E.; RICORT, J. M.; LEMOINE, J.; ZHANG, M.; HONDERMARCK, H.; LE BOURHIS, $X$. Proteomics demonstration that normal breast epithelial cells can induce apoptosis of breast cancer cells through insulin-like growth factor-binding protein-3 and maspin. Molecular and Cellular Proteomics, v. 6, n. 7, p. 1239-1247, 2007. Disponível em:

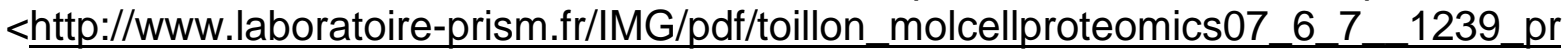
oteomics breastcancer.pdf> Acesso em: 20 abr.2016.

WILSON, D.E.; REEDER, D. A. M. Mammal Species of the World. A Taxonomic and Geographic Reference, 3rd ed. Baltimore: Johns Hopkins University Press, 2005. 2142p. Disponível em: <http://vertebrates.si.edu/msw/mswCFApp/msw/index. cfm> Acesso em: 19 dez. 2015. 